\title{
Omics multi-layers networks and identification of genes involved in fat storage and metabolism in poultry using interactomics approach
}

abolfazl bahrami ( $\sim$ a.bahrami@ut.ac.ir)

University of Tehran https://orcid.org/0000-0001-7330-4134

Farzad Ghafouri

University of Tehran

Mostafa Sadeghi

University of Tehran

Seyed Reza Miraei-Ashtiani

University of Tehran

\section{Research article}

Keywords: Lipid metabolism, Transcriptome, Systems biology, Interactive bipartite network, Multi- Omics layer

Posted Date: June 8th, 2020

DOl: https://doi.org/10.21203/rs.3.rs-30697/v1

License: () (1) This work is licensed under a Creative Commons Attribution 4.0 International License. Read Full License 


\section{Abstract \\ Background}

Fatty acid metabolism in animals has a major impact on production and disease resistance traits. According to the high rate of interactions between lipid metabolism and its regulating properties, a holistic approach is necessary.

\section{Methods}

To study multi-omics layers of adipose tissue and identification of genes involved in fat metabolism, storage and endocrine signaling pathways in two groups of broiler chickens with high and low abdominal fat, high-throughput screening (HTS) techniques were used. The Gene-miRNA interacting bipartite and metabolic-signaling networks were reconstructed using their interactions.

\section{Results}

In the analysis of microarray and RNA-Seq data, 1835 genes were detected by comparing the identified genes with significant expression differences. Then, by comparing, 34 genes and 19 miRNAs were detected as common and main nodes. The literature mining approach was used and 7 genes were identified and added to the common gene set. Module finding revealed three important and functional modules. The detected modules 1, 2, and 3 were involved in the PPAR signaling pathway, biosynthesis of unsaturated fatty acids, and Alzheimer's disease metabolic pathway, adipocytokine, insulin, PI3K-Akt, mTOR and AMPK signaling pathway.

\section{Conclusions}

This approach revealed a new insight for a better understanding of the biological processes associated with adipose tissue.

\section{Background}

Total carcass fat of broilers varies depending on sex, bird age, nutrition, and genetic factors and it is about $12 \%$ [1]. The main fat stored in broiler carcass is two kinds of subcutaneous fat and ventricular fat, Which a portion of carcass fat (about 18 to 22 percent) is stored in the ventricular area [2]. In the following, in humans, as the main consumer of poultry meat, over-fat storage in skeletal muscle is associated with metabolic diseases such as type 2 diabetes, cardiovascular disease and subsequently will lead to the risk of a heart attack. Fat production in poultry is a high-inheritance polygenic trait regulated by various behavioral, environmental, and hormonal factors [3].

Many studies have been reported identified genes related to storage lipids in broilers $[4,5,6]$. On the other hand, the integration of high-throughput genomic DNA and RNA sequencing leads to identify genomic regions that control traits at the whole genome scale [7]. Some studies that using high-density microarrays in two groups of obese (high-fat) and lean (low-fat) birds indicated genes associated with lipogenic pathways [8,9]. Comparing the expressed genes, a large number of genes were identified in endocrine, hemostatic, lipolytic and lipid transduction in abdominal fat of chickens with low ventricular fat [10]. As well as, the visceral fat of broilers with high abdominal fat indicated high expression of numerous transcription factors, enzymes, and transducers involved in adipogenesis and lipogenesis [10].

In addition to identifying genes and pathways associated with lipid metabolism, the mechanism for regulating their expression should also be examined. MicroRNAs, are regulatory molecules with a length of 19-25 nucleotides [11]. Mature microRNAs leads to decomposition or inhibit translation by complete or partial coupling to target mRNAs (usually paired with the $3^{\prime}$ UTR region) [12]. By increasing fields in biology research as well as, introducing other fields such as biological mathematics and statistics, we have witnessed the emergence of various areas in biology. One of the most important areas is the application of bioinformatics and systems biology and integrated multi-omics data. In the systems biology, attempted to identify the cellular system and formulate cell behaviors and then design a cell model by combining genomic, transcriptomic, proteomic, and metabolomic layers [13]. In this regards, interactive bi-partite networks of Gene-miRNA are used in a number of studies to discover functional modules $[14,15,16]$.

However, identification of upstream and downstream genes, reconstruction of networks, bipartite interaction network of Gene-miRNA and metabolic-signaling network involved in metabolism and adipose storage especially abdominal fat by using high-throughput data in broilers have not been reported. Regarding that fat storage in broilers is considered as an important economic trait in relation to high growth rate, and based on previous studies of fat metabolism in the body and signaling pathways related to fat storage and its transmission in laboratory species as well as broilers, it was assumed that the two broiler groups of high-abdominal fat and low-abdominal fat have expression differences in metabolism and fat-storage genes.

Accordingly, this study aims to use integration of RNA-Seq and microarray data to identify and classify candidate genes that involved in lipolysis and lipogenesis, reconstruction of the interactive bi-partite network of Gene-miRNA, identification of functionally-relevant modules as well as regeneration of the metabolic-signaling network associated with the process of metabolism and fat storage in broilers.

\section{Methods}

Figure 1 shows the overall workflow for analyzing and finding functionally-relevant modules with high and low-fat storage in the broilers' ventricle. 


\section{Data analysis}

In the biological system and the reconstruction of biological networks, namely, gene regulation, interactions, protein-protein interaction, and metabolic networks, the first step is to collect and evaluate the available data. In this regard, the main data of this study were obtained by investigating and reviewing related articles and collecting microarray and RNA-Seq data from different databases.

By searching the GEO (Gene Expression Omnibus) database (www.ncbi.nlm.nih.gov/geo) and ArrayExpress (www.ebi.ac.uk/arrayexpress) for abdominal fat in various species especially for Gallus gallus domesticus, a significant amount of data were collected. The accession numbers for the RNA-Seq and microarray datasets were showed in Table 1.

Table 1

GEO access codes for RNA-Seq and microarray datasets

\begin{tabular}{|cllllll|}
\hline NO. & Data Type & GSE & Platforms & No. Sample(s) & Contributor(s) \\
\hline 1 & RNA-Seq & GSE49121 & GPL16133 (Illumina HiSeq 2000) & 16 & Resnyk et al., 2017 \\
\hline 2 & RNA-Seq & GSE42980 & GPL16133 (Illumina HiSeq 2000) & 24 & Resnyk et al., 2015 \\
\hline 3 & Microarray & GSE37585 & GPL1731 (DEL-MAR 14K Integrated Systems) & 24 & Resnyk et al., 2013 \\
\hline 4 & Microarray & GSE8812 & GPL1731 (DEL-MAR 14K Integrated Systems) & 24 & Cogburn, 2007 \\
\hline 5 & Microarray & GSE45825 & GPL1731 (DEL-MAR 14K Integrated Systems) & 24 & Resnyk et al., 2017 \\
\hline 6 & Microarray & GSE10052 & GPL1731 (DEL-MAR 14K Integrated Systems) & 8 & Byerly et al., 2010 \\
\hline 7 & Microarray & GSE3867 & GPL3265 (Chicken cDNA DDMET 1700 array version 1.0) & 28 & Bourneuf et al., 2006 \\
\hline 8 & Microarray & GSE118611 & GPL25454 (Arraystar Mouse ncRNA microarray V3B) & 12 & Shen et al., 2019 \\
\hline
\end{tabular}

\section{Analysis Of Microarray Data}

Microarray data were pre-processed in software R, using package Lumi [17] and Affy [18]. The processed data were then evaluated using packages Limma [19], GEOquary [20], and Biobase [21]. Among the number of identified genes, the genes which were common in terms of five accession numbers were identified; and the gene list was considered as a gene set 1.

\section{Analysis Of RNA-Seq Data}

Various software were used to analyze the RNA-Seq data related to the accession numbers Initially, FastQC quality control software [22] was used to control the quality of existing data. After converting the file format, the data required to trim the adapters using Trimmomatic software [23]. For aligning, TopHat2 software [24] was used to map the reads on the reference genome of the chicken species (Gallus Gallus domesticus). Finally, different gene expression was performed using CuffDiff software [25]. The genes which were common in terms of accession numbers were identified and considered as a gene set 2.

\section{Functional Gene Set Annotation And Enrichment}

\section{Main Gene List}

Genes with significant differences related to microarray and RNA-Seq data were examined and listed as gene set 1 and 2 , respectively. Finally, genes that were common in two sets were chosen as the main gene list.

\section{Idetification Of miRNAs And Target Genes}

Accession number GSE118611 [29], which related to miRNA in mouse species and associated with lipid metabolism, was analyzed. For this purpose, Blast N (available tool in miRBase database) was used [30], miRNAs of Gallus gallus domesticus that were involved in lipid metabolism were detected. miRNA target genes was performed based on the bioinformatics platform miRWalk 3.0 [31]. The platform integrates information from different miRNA-target databases and TargetScanVert software [32]

\section{Reconstruction Of Omics Multi-layers Networks}

STRING [33] and GeneMania databases [34] were used for detecting interactions between different omics layers. Protein-protein interaction (PPI) data were abstracted from Biomolecular Interaction Network Database (BIND), Database of Interacting Proteins (DIP), Biological General Repository for Interaction Datasets (BioGRID) and Mammalian Protein-Protein Interactions Database (MIPS). Networks were reconstructed using Cytoscape 3.7.2. [35]. The metabolicsignaling pathways involved in the lipid metabolism and storage was reconstructed by different databases and Cell Designer version 4.4.2 [36]. 


\section{Modules And Hub Nodes Detection}

For finding sub-graphs and hub nodes, MCODE, one of the Cytoscape plugins was used [37].

\section{Results}

2914 genes were extracted after analyzing the microarray data to express the gene differences; and 612, 107, 582,104 and 46 genes were respectively identified after considering the expression change threshold in each of the available accession numbers, GSE37585, GSE8812, GSE45825, GSE10052, and GSE3867; and the difference in numbers of genes refers to differences in time and place of broiler chicken farming. In general, 1451 genes were significantly different. In the data analysis of RNA-Seq, 1867 genes were identified; and then 314 and 70 genes were detected after considering the threshold $(P<0.00001)$ of expression change in accession numbers of GSE49121 and GSE42980, respectively. A total of 384 genes were significantly different.

\section{Identification Of miRNA And Target Genes}

In the data analysis of microRNA to express differences in miRNAs, 250 miRNAs were detected, and 19 miRNA and 15 genes were identified by taking into account the threshold (LogFC <-2, LogFC > 2 and P-value < 0.00001 ) of expression change in the accession number of GSE118611 to identify suppressing miRNAs as well as target genes in the same gene set (Table 2). Finally, the data analysis of miRNAs indicated 11 miRNAs with higher expression and 8 miRNAs with lower expression in the greater abdominal fat storage compared to the lower abdominal fat storage. 
Table 2

Genes and miRNAs, Annotation, Lipogenesis and Lipolysis genes involved in fat metabolism and deposition. Upregulated and Downregulated abdominal

\begin{tabular}{|c|c|c|c|c|c|c|c|c|}
\hline Lipogenesis & & & & & & Lipolysis & & \\
\hline Gene & Annotation & Gene Expression & & miRNA Expressio & & Gene & Annotation & Gene Express \\
\hline & & Downregulation & Upregulation & Downregulation & Upregulation & & & Downregulati \\
\hline & & $(\log \mathrm{FC})$ & $(\log \mathrm{FC})$ & $(\log \mathrm{FC})$ & $(\log \mathrm{FC})$ & & & $(\log \mathrm{FC})$ \\
\hline THBS1 & Thrombospondin 1 & * & & - & $\begin{array}{l}\text { gga-miR- } \\
6554-5 p\end{array}$ & COLEC12 & $\begin{array}{l}\text { Collectin } \\
\text { Subfamily } \\
\text { Member } 12\end{array}$ & * \\
\hline & & & & & $\begin{array}{l}\text { gga-miR- } \\
6667-5 p\end{array}$ & & & \\
\hline & & & & & $\begin{array}{l}\text { gga-miR- } \\
6562-3 p\end{array}$ & & & \\
\hline ANXA7 & Annexin A7 & * & & - & gga-miR-466 & RGS19 & $\begin{array}{l}\text { Regulator Of G } \\
\text { Protein Signaling } \\
19\end{array}$ & * \\
\hline TMEM258 & $\begin{array}{l}\text { Transmembrane } \\
\text { Protein } 258\end{array}$ & & * & - & - & HTR7L & $\begin{array}{l}\text { 5- } \\
\text { hydroxytryptamine } \\
\text { receptor } 7 \text { like }\end{array}$ & \\
\hline DHCR7 & $\begin{array}{l}\text { 7- } \\
\text { Dehydrocholesterol } \\
\text { Reductase }\end{array}$ & & * & - & - & G6PC & $\begin{array}{l}\text { Glucose-6- } \\
\text { Phosphatase } \\
\text { Catalytic Subunit }\end{array}$ & \\
\hline FADS2 & $\begin{array}{l}\text { Fatty Acid } \\
\text { Desaturase } 2\end{array}$ & & * & - & - & HMGCR & $\begin{array}{l}\text { 3-Hydroxy-3- } \\
\text { Methylglutaryl- } \\
\text { CoA Reductase }\end{array}$ & \\
\hline FASN & $\begin{array}{l}\text { Fatty Acid } \\
\text { Synthase }\end{array}$ & & * & - & - & ACAT1 & $\begin{array}{l}\text { Acetyl-CoA } \\
\text { Acetyltransferase } \\
1\end{array}$ & * \\
\hline INSIG2 & $\begin{array}{l}\text { Insulin Induced } \\
\text { Gene } 2\end{array}$ & & * & $\begin{array}{l}\text { gga-miR-7444- } \\
5 p\end{array}$ & - & ADH1C & $\begin{array}{l}\text { Alcohol } \\
\text { Dehydrogenase } \\
\text { 1C (Class I), } \\
\text { Gamma } \\
\text { Polypeptide }\end{array}$ & * \\
\hline LCAT & $\begin{array}{l}\text { Lecithin- } \\
\text { Cholesterol } \\
\text { Acyltransferase }\end{array}$ & & * & - & - & APP & $\begin{array}{l}\text { Amyloid Beta } \\
\text { Precursor Protein }\end{array}$ & * \\
\hline MVD & $\begin{array}{l}\text { Mevalonate } \\
\text { Diphosphate } \\
\text { Decarboxylase }\end{array}$ & & * & - & - & EHHADH & $\begin{array}{l}\text { Enoyl-CoA } \\
\text { Hydratase And 3- } \\
\text { Hydroxyacyl CoA } \\
\text { Dehydrogenase }\end{array}$ & * \\
\hline SCD & $\begin{array}{l}\text { Stearoyl-CoA } \\
\text { Desaturase }\end{array}$ & & * & - & - & GAMT & $\begin{array}{l}\text { Guanidinoacetate } \\
\mathrm{N}- \\
\text { Methyltransferase }\end{array}$ & * \\
\hline SREBF1 & $\begin{array}{l}\text { Sterol Regulatory } \\
\text { Element Binding } \\
\text { Transcription } \\
\text { Factor } 1\end{array}$ & & * & - & - & HADHB & $\begin{array}{l}\text { Hydroxyacyl-CoA } \\
\text { Dehydrogenase } \\
\text { Trifunctional } \\
\text { Multienzyme } \\
\text { Complex Subunit } \\
\text { Beta }\end{array}$ & * \\
\hline APOA1 & Apolipoprotein A1 & * & & - & - & HSD17B4 & $\begin{array}{l}\text { Hydroxysteroid 17- } \\
\text { Beta } \\
\text { Dehydrogenase } 4\end{array}$ & * \\
\hline $\mathrm{BCO} 2$ & $\begin{array}{l}\text { Beta-Carotene } \\
\text { Oxygenase } 2\end{array}$ & * & & - & - & HSD17B6 & $\begin{array}{l}\text { Hydroxysteroid 17- } \\
\text { Beta } \\
\text { Dehydrogenase } 6\end{array}$ & * \\
\hline CYP27A1 & $\begin{array}{l}\text { Cytochrome P450 } \\
\text { Family } 27 \\
\text { Subfamily A } \\
\text { Member } 1\end{array}$ & * & & - & - & IRS1 & $\begin{array}{l}\text { Insulin Receptor } \\
\text { Substrate } 1\end{array}$ & * \\
\hline
\end{tabular}




\begin{tabular}{|c|c|c|c|c|c|c|c|}
\hline \multicolumn{5}{|c|}{ Lipogenesis } & \multicolumn{3}{|c|}{ Lipolysis } \\
\hline CYP2E1 & $\begin{array}{l}\text { Cytochrome P450 } \\
\text { Family } 2 \\
\text { Subfamily E } \\
\text { Member } 1\end{array}$ & * & - & - & $\mathrm{PHYH}$ & $\begin{array}{l}\text { Phytanoyl-CoA 2- } \\
\text { Hydroxylase }\end{array}$ & * \\
\hline \multirow[t]{4}{*}{ SLC2A2 } & $\begin{array}{l}\text { Solute Carrier } \\
\text { Family } 2 \\
\text { (Facilitated } \\
\text { Glucose } \\
\text { Transporter), } \\
\text { Member } 2\end{array}$ & * & - & - & SOD3 & $\begin{array}{l}\text { Superoxide } \\
\text { Dismutase } 3\end{array}$ & * \\
\hline & GLUT2 & & & & & & \\
\hline & & & & & TP53 & Tumor Protein P53 & * \\
\hline & & & & & UCP3 & $\begin{array}{l}\text { Uncoupling } \\
\text { Protein } 3 \\
\text { (Mitochondrial, } \\
\text { Proton Carrier) }\end{array}$ & * \\
\hline
\end{tabular}

Identification of common genes in gene sets 1 and 2

384 genes in data of RNA-Seq and 1451 genes in the microarray data had differentially expressed genes (DEG). 34 genes were common in two gene sets 1 and 2 relating to microarray data and RNA-Seq data sets, respectively.

In this regard, 16 and 18 genes were related to lipogenesis and lipolysis processes (Table 2). THBS1 and INS/G2 genes in the gene set associated with the lipogenesis process as well as COLEC12, HMGCR, APP and IRS1 genes in the gene set associated with the lipolysis process had the highest level of suppression by miRNAs.

Nine out of 16 genes had higher expression in the gene set associated with the lipogenesis; and 15 out of 18 genes in the gene set associated with the lipolysis had lower expression in higher abdominal fat tissue compared to the lower abdominal fat tissue (Table 2).

\section{Reference Gene List}

Articles related to the process were also reviewed to ensure the accuracy and seven genes, which did not exist in the list of previous data, were selected and added to the gene list. The selected seven genes included BACE1, BACE2, PSEN1, PSEN2, PERP, SIK1 and LOC421682 genes. It should be noted that the list of genes in Table 2 (34 genes) and seven genes identified by investigating the sources were considered as the list of reference genes (41 genes).

\section{Gene Interaction Network, GO Terms And Pathways}

Figure 2 shows the network of the reconstruction of genes interactions, GO terms and pathways. In this network, APP, SREBF1, HMGCR, FADS2, SCD, ACAT1, FASN, HADHB and EHHADH genes had the highest interaction with other genes in the network.

\section{Reconstruction Of The Interactive Bipartite Network Of Gene-miRNA}

The network contains 49 nodes (including 32 genes and 17 miRNAs) and 95 edges. The reconstructed network with .cys format was stored for other analyses (Fig. 3).

\section{Important And Functional Network Modules}

According to interactive bipartite network of Gene-miRNA and finding the relevant sub-networks or modules, 3 modules contained 31 genes and 7 miRNA as presented in Table 3. The table also presents important signaling pathways and cellular processes (metabolic pathways) in which the relevant modules are involved (Fig. 2). 
Table 3

Modules, genes and miRNAs, signaling pathway and phenotypic explanations in the integrated gene-miRNA bipartite network involved in fat metabolism and deposition. Upregulated and Downregulated abdominal Fat in genetically fat compared with lean chickens.

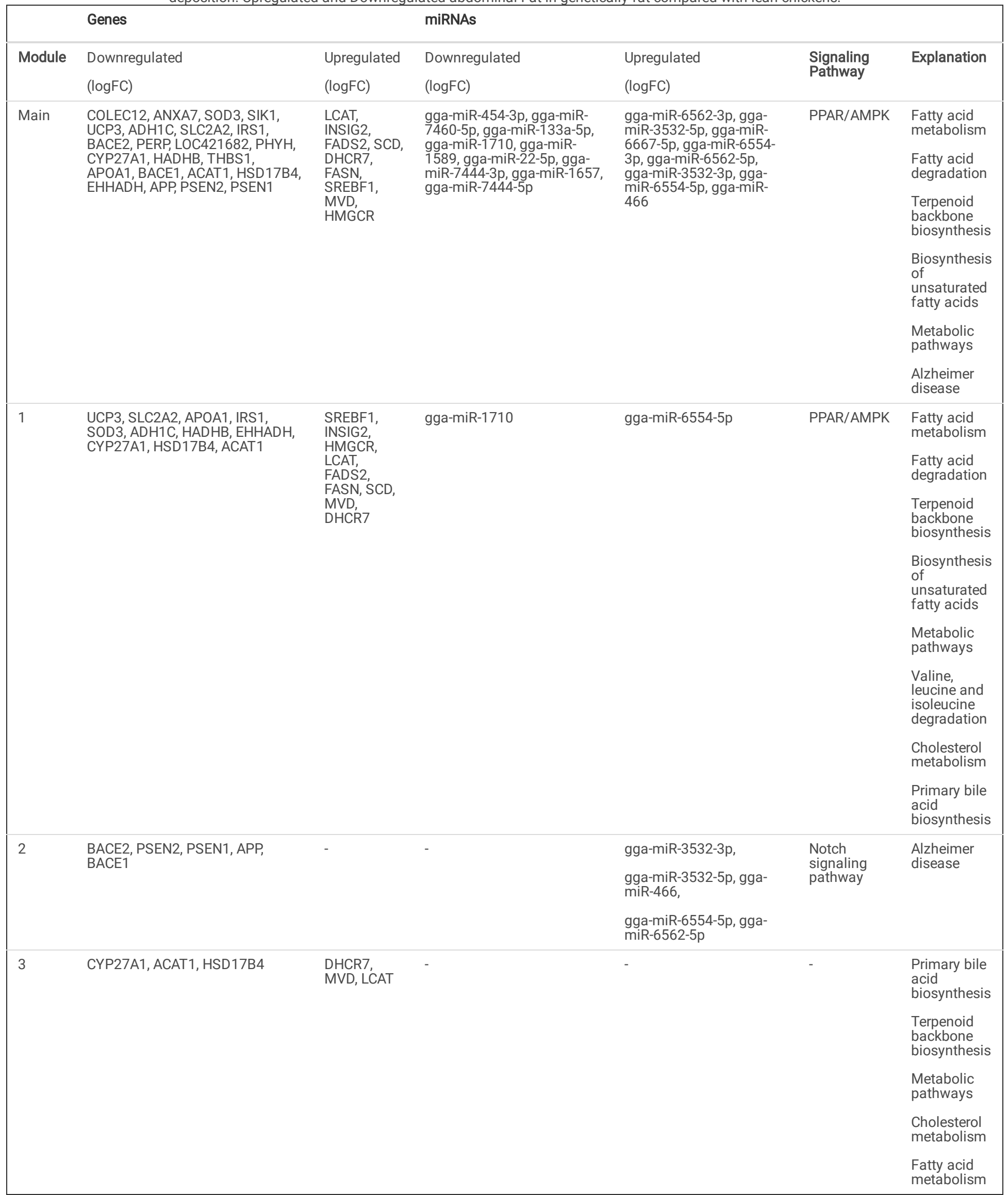

Module 1 contains 22 nodes (20 genes and 2 miRNAs) and 47 edges. Module 2 contains 10 nodes ( 5 genes and 5 miRNAs) and 16 edges; and Module 3 includes 6 nodes ( 6 genes) and 6 edges. 


\section{Reconstruction Of The Metabolic-signaling Network}

Signaling pathways include the Notch signaling pathways relating to Alzheimer's disease, PPAR, adipocytokine, insulin, PI3K-Akt, mTOR, and AMPK signaling pathway respectively (Fig. 7).

\section{Discussion}

The priority of abdominal fat tissue in broiler chickens to identify genes involved in metabolism and fat storage is due to the fact that it can be as a prior model in other species and individuals of a species due to its specific metabolic characteristics [38]. The present study detected a total of 34 common genes that played roles in the main process of synthesis route control, metabolism and fat storage, and signaling pathways of endocrine glands activated by adipokines, AMPK and PPAR.

The lower expression of a large number of genes associated with the lipolysis indicated a reduction in decomposition of fats and then an increase in the anabolism and fat storage in broiler chickens, especially in abdominal fat tissue. On the contrary, the higher expression of a large number of genes in the gene set associated with the lipogenesis confirms the increase in metabolism and abdominal fat storage.

Chickens with greater abdominal fat had hyperplasia and hypertrophy of fat cells at younger ages compared to chickens with lower abdominal fat. SREBF1, SREBF2, SCD, FASN and THRSPA were among the most important genes that play major roles in fat storage and metabolism [10]. Hub genes in this study were $A P P$, SREBF1, HMGCR, FADS2, SCD, ACAT1, FASN, HADHB and EHHADH (Fig. 2).

APP gene is a cell surface receptor and an extra-membrane precursor protein that is decomposed by enzymes to form a number of peptides. Some of these peptides are secreted and can be bound to an acetyl transferase complex APBB1/TIP60 to strengthen the transcription activities, while other proteins create amyloid plaques in brains of patients with Alzheimer's disease [39]. It enhances the transcription through binding to APBB1/KAT5, and inhibits Notch signals through interaction with Numb.

Sterol regulatory element-binding transcription factor 1 (SREBF1) is a protein encoding gene. Fatty liver disease is a SREBF1 gene-related disease; and mTOR signaling pathway is a pathway associated with SREBF1. Annotation of this gene includes the DNA and chromatin binding transcription factor activity and it regulates the rate of transcription of the $L D L$ receptorgene, Fatty acid and the cholesterol synthesis pathway to a lesser extent.

HMGCR or 3-hydroxy-3-methylglutaryl coenzyme A reductase is a protein encoding. The Terpenoid backbone biosynthesis pathway is a pathway associated with this gene [40].

Fatty acid desaturase 2 (FADS2) is a protein-encoding gene with pathways such as fatty acid beta-oxidation (peroxisome) and Alpha-linolenic acid metabolism. This gene is a part of the lipid metabolic pathway that catalyzes the biosynthesis of unsaturated fatty acids from unsaturated fatty acids of linoleic acid (18: $2 n-6)$ and linolenic acid (18: 3n-3) [41].

Stearoyl-coenzyme a desaturase $(S C D)$ encodes the enzyme that is involved in the biosynthesis of fatty acids, so that it is first responsible for the synthesis of oleic acid. Its produced protein belongs to the desaturase fatty acid family [42].

ACAT1 (Acetyl-Coenzyme A acetyltransferase 1) is a protein-encoding gene that involved in metabolic pathways of ketone body metabolism and the Terpenoid backbone biosynthesis. The gene plays a key role in the ketone body metabolism [43].

FASN (Fatty acid synthase) is a protein-encoding gene with pathways such as the metabolism of water-soluble vitamins and cofactors as well as the enzymatic complex pathway of AMPK.

Hydroxyacyl-CoA Dehydrogenase Trifunctional Multienzyme Complex Subunit Beta $(H A D H B)$ is a protein-encoding gene with pathways such as beta-oxidation of mitochondrial fatty acids and biosynthesis of glycerophospholipids [44].

EHHADH (Enoyl-CoA Hydratase And 3-Hydroxyacyl CoA Dehydrogenase) is a protein encoding gene with pathways such as PPAR alpha pathway and propanoate metabolism. The gene annotation includes the binding of signaling receptors and oxidoreductase activity [45]. Given the ontology expression and functions of important and main genes in the network of genes interactions, it can be stated that these genes are the main genes in the metabolism and fat storage as well as the signaling pathways of endocrine glands, especially AMPK and PPAR signaling pathways.

In Fig. 3, green quadrilateral nodes representing the genes with the highest interaction in the network are the main candidates in lipid metabolism and storage and play roles in the list of desired gene (reference), metabolic and signaling pathways. The genes with the highest repression levels include $T H B S 1$, SIK1, COLEC12, and BACE1 respectively.

A combined biological system approach is used to detect metabolic and signaling pathways associated with the interactive bipartite network of Gene-miRNA in the process of fat storage and metabolism of broiler chicken. Fat stored in the skeletal muscles plays roles in important metabolic processes such as immune function, food consumption, hormone sensitivity and relevant signaling pathways [46].

In module 1, gga-miR-1710 suppress HMGCR Gene. gga-miR-1710 has an expression reduction. Its target gene represents the increased expression in higher abdominal fat tissue compared to lower abdominal fat tissue. The gene is classified into a set of genes associated with the lipolysis process. Therefore, reducing expression of gga-miR-1710 and increased gene expression of $H M G C R$ lead to the lipolysis process, thereby reducing the abdominal fat. $H M G-C o A$ reductase protein-encoding gene is the cholesterol synthesis limiting enzyme that regulates the product of catalyzed reaction by reductase through a negative 
feedback mechanism by sterols and non-sterol metabolites derived from mevalonate. The enzyme in mammalian cells is usually suppressed by cholesterol derived from the construction and destruction of low-density lipoprotein (LDL) through the LDL receptor [40].

$S C D$ gene indicates the higher expression in larger abdominal fat tissue compared to the lower abdominal fat tissue. $S C D$ gene is put into the set of genes associated with the lipogenesis process. Therefore, increasing the $S C D$ gene expression raises the amount of fat storage in the body, especially in abdominal part. $S C D$ gene (Stearoyl-coenzyme A desaturase) is a protein-encoding gene with pathways including adipogenesis and angiopoietin such as the protein 8 regulatory pathway. It also plays an important role in the lipid biosynthesis and regulating the expression of genes in the mitochondrial fatty acid oxidation and lipogenesis cycle [47].

gga-miR-6554-5p suppress the IRS1 gene. This miRNA has higher expression; and its target gene shows a lower expression in greater abdominal fat tissue compared to the lower abdominal fat tissue. IRS1 gene is among the set of genes associated with the lipolysis process. Therefore, increasing expression of gga-miR-6554-5p miRNA decreases the IRS1 gene expression, thereby reducing the amount of fat catabolism and increasing the abdominal fat storage and anabolism. IRS1 gene encodes a protein that is phosphorylated by insulin receptor tyrosine kinase. Mutations in the gene are associated with type 2 diabetes and insulin resistance [48].

SREBF1 gene shows the higher expression in greater abdominal fat tissue compared to the lower abdominal fat tissue. The gene is among the set of genes associated with lipogenesis process. The higher SREBF1 gene expression increases the abdominal fat storage and anabolism. SREBF1 gene encodes the Helix-Loop-Helix-Leucine Zipper (bHLH-Zip) that binds the sterol-1 regulator. It is also found in the promoter for low density lipoprotein receptor gene and other genes in the sterol biosynthesis [49].

In this module, HMGCR gene is suppressed by miRNAs. The gene is associated with the lipolysis process. Therefore, its suppression can prevent the fat tissue catabolism and lead to the higher fat storage and anabolism in abdominal fat tissue of broiler chickens. In this module, there are six genes, namely $H M G C R$, SREBF1, SCD, FASN, HADHB and ACAT1 with certain color (green) and have the highest interaction with other genes involved in the module. The enzyme which is encoded by FASN gene is a multi-functional protein. Its main function is the canalization of the synthesis of Palmitate from Acetyl-CoA and Malonyl-CoA in the presence of NADPH to long-chain saturated fatty acids. ACAT1 gene encodes a topical mitochondrial enzyme that catalyzes the reversible form of Acetoacetyl CoA from two acetyl CoA molecules. $H A D H B$ Gene is responsible for encoding the beta subunit of mitochondrial function protein and catalyzes three final three stages of the mitochondrial beta-oxidation process of long-chain fatty acids [44].

The gene set of this module, as presented in Table 3, encodes signaling pathways AMPK and PPAR as well as metabolic pathways of fatty acid synthase, unsaturated fatty acid synthase, and cholesterol metabolism pathways. Therefore, it can be concluded that the module and genes involved in the process can be functional modules associated with abdominal fat metabolism and storage in broiler chickens.

The receptor increases the insulin-mediated glucose uptake and improves the blood lipid profile by regulating the lipid metabolism, glucose, and free fatty acid oxidation [50]. Target genes of peroxisome proliferator-activated receptors are related to several proteins that are necessary for absorption, intercellular transfer, and beta-oxidation of fatty acids, while they include Fatty acid transport protein, Fatty Acid Translocase enzyme, and synthase enzyme involved in the production of acetyl CoA (for long-chain fatty acids) and Carnitine palmitoyltransferase I [51]. Peroxisome proliferator-activated receptors play roles in the regulation of the gene transcription process (P2) of fat cells, so that the lean and fat-free meat can be produced by manipulation of the differentiation of fat tissue cells and their fat content through these receptors.

The cellular response to insulin includes the regulation of blood sugar levels by increasing the glucose uptake in muscles and fat tissues in a way that energy reserves in fat tissue, liver and muscles increase by stimulating the lipogenesis, glycogen synthesis, and protein synthesis. Insulin signaling pathway decreases the glucose production by the liver and the total inhibition of energy stored through lipolysis, glycogenolysis and breakdown of proteins. This pathway also acts as a growth factor and stimulates the cell growth, differentiation and survival [52]. The insulin signaling pathway is an important biochemical pathway that regulates some basic biological functions such as glucose and lipid metabolism, synthesis of proteins, cell proliferation and differentiation, and apoptosis [53].

Signaling pathway of Phosphatidylinositol (PI3K)/ Protein Kinase B (Act) is involved in the regulation of many physiological cell processes by activating effective cross-downstream molecules that play important roles in the cellular cycle, growth and proliferation [54].

Mammalian Target of Rapamycin (mTOR) signaling pathway has both internal and external signals and acts as a main regulator of cellular metabolism, growth, proliferation, and survival. Exploration carried out over the past decade indicates that the mTOR signaling pathway is activated in various cellular processes such as tumor formation and angiogenesis, insulin resistance, lipid metabolism, and lymphocyte T activation, and is regulated in human diseases such as cancer and type 2 diabetes [55].

In module 2, APP gene plays the main role. The gene is suppressed by gga-miR-6554-5p. gga-miR-6554-5p represents the up-regulation; and its target gene represents the down-regulation in greater abdominal fat tissue compared to the lower abdominal fat tissue. APP gene is a set of genes associated with the lipolysis process. Therefore its repression by miRNAs in humans is necessary. In poultry, its lower expression is equivalent to a decrease in abdominal fat; and a decrease in body fat is equivalent to an increase in proliferation performance and other functional traits. Increased body weight or obesity caused by increased body fat storage is characterized by excessive accumulation of fat in the body and increased levels of adipokines and inflammatory cytokines. This indicates an increased risk of Alzheimer's disease, type 2 diabetes, and cardiovascular diseases. It has been recently found that the gene expression level of $A P P$ increases as brain tissue fat and the fat storage tissues increase in the body [56].

gga-miR-6554-5p and gga-miR-466 miRNAs suppress BACE1 gene. These two miRNAs represent the up-regulation and their target genes indicate the downregulation in greater abdominal fat tissue compared to lower abdominal fat tissue. BACE1 gene encodes an enzyme that cuts the amyloid precursor protein 
(APP) and produces Amyloid beta peptides that cause amyloid plaque in brains of patients with Alzheimer's [57, 58]. BACE2 is an important paralog of this gene.

gga-miR-6562-5p and gga-miR-3532-5p suppress the PSEN1 gene. These two miRNAs indicate the up-regulation; and their target gene indicates the downregulation in the greater abdominal fat tissue compared to the lower abdominal fat tissue. PSEN1 encodes a protein that is called Presenilin 1 . Presenilins are $A P P$ regulators according to their effects on gamma secretase as APP-decomposing enzymes [59].

PSEN2 gene, which has about $67 \%$ of similarity to PSEN1 gene, was identified after PSEN1 gene. PSEN2 gene indicated a lower expression in greater abdominal fat tissue compared to the lower abdominal fat tissue. PSEN2 gene is a protein encoding gene with associated diseases such as Alzheimer's disease and heart muscle diseases. It encodes the intermediate signaling Presenilin and Wnt/ Hedgehog/Notch pathways [60].

gga-miR-3532-3p suppress BACE2 Gene. The miRNAs indicate the up-regulation; and their target gene, BACE2, indicates the low expression in greater abdominal fat tissue compared to lower abdominal fat tissue. BACE2 gene encodes a full membrane glycoprotein that is known as an Aspartic protease [61].

Five genes are involved in this module that is associated with the pathway of Alzheimer's disease. This module and its involved genes encode the Notch signaling pathway and metabolic pathway of Alzheimer's disease. Five genes involved in the module indicated the low expression in fat tissue in greater abdominal fat tissue compared to lower abdominal fat tissue. APP gene plays roles in the lipolysis process; and BACE1, BACE2, PSEN1 and PSEN2 genes play roles in the lipogenesis process. In this module, the lower $A P P$ gene expression and lower expression of other genes in the process of lipolysis reduce the fat accumulation, and thus reduce the risk of Alzheimer's disease. If amounts of fat stored in the body increases, it leads to the higher expression of $B A C E 1$, $B A C E 2, P S E N 1$ and PSEN2 genes, especially BACE1 genes, thereby leading to breakage of the protein encoded by APP gene and creation of conditions for development of Alzheimer's disease.

Nutrition of unsaturated fatty acids can play a significant role in reducing Alzheimer's disease. A study indicated that metabolisms of unsaturated fatty acids are significantly regulated in brains of patients with different degrees of Alzheimer's pathology [62]. Another study indicated that the high intake of unsaturated fats could have a protective role against Alzheimer's disease, while the consumption of saturated or trans-unsaturated fats increases the risk of developing Alzheimer's disease [63].

In module 3, MVD gene indicated the higher expression in the greater abdominal fat tissue compared to the lower abdominal fat tissue. MVD gene is a set of genes associated with the lipogenesis process. This gene encodes a Mevalonate diphosphate decarboxylase (MVD) enzyme. Its related pathways include the protein metabolism and synthesis of available substrates in the biosynthesis of $\mathrm{N}$-glycans. $D H C R 7$ gene is another important gene of this module, indicating the higher expression in the greater abdominal fat tissue compared to the lower abdominal fat tissue. DHCR7 or 7-dehydrocholesterol reductase is a proteinencoding gene that plays role in eliminating an enzyme that creates a double bond of C (7-8) in loop B of Sterol and catalyzes the conversion of 7dehydrocholesterol to cholesterol. Cholesterol I biosynthesis and vitamin D metabolism are its associated pathways. TM7SF2 gene is an important paralog of this gene [www.genecards.org, 64].

ACAT1 gene is another important gene in this module indicating the low expression in greater abdominal fat tissue compared to the lower abdominal fat tissue. This gene catalyzes Acetoacetyl CoA using two acetyl coenzyme A molecules [43].

Given the roles of three main genes involved in the structure of this module as well as using the online database, this module encodes metabolic pathways of cholesterol metabolism and the metabolism of fatty acids.

In the Notch signaling pathway, Notch receptor is phosphorylated and it activates NICD gene in collaboration with PSEN1 gene as a $\mathrm{Y}$-secretase complex. Inside the cell nucleus, this gene encodes the sequence of FABP7 gene and triggers the construction of FABP7 mRNA by cooperation with RBPJ/CBF1 complex. FABP gene is activated by two phosphorylated receptors, called FATP and FATCDB6, in the cell membrane. Thereafter, three signaling complexes, $P P A R_{\alpha} / R X R \rrbracket P P A R_{\beta} / R X R$ and $P P A R_{\gamma} / R X R$, are activated. These signaling pathways encode genes relating to the fat storage and metabolism in the cell nucleus. These complexes in the nucleus are related to Lipid transport, Lipogenesis, Cholesterol metabolism, and Fatty acid oxidation, leading to the process of lipid metabolism by transcription and translation of the genes. In the signaling path of PPAR, $P P A R$ / $R X R$ complex is associated with the insulin-related signaling pathway through the phosphorylated mTORC1 gene in the mTOR pathway. The phosphorylation of this gene results in activation of $P P A R_{\gamma} / R X R$ complex. AMPK signaling pathway is also associated with $m T O R C 1$ gene and has an inhibitory effect, in a way that the AMPK pathway prevents the phosphorylation of $m T O R C 1$ gene, so that $P P A R_{\gamma} / R X R$ complex is not activated; and the lipid metabolism process (e.g. lipogenesis, cholesterol and oxidation metabolisms) is not performed. Two signaling pathways, PPAR (the main pathway of lipid metabolism) and AMPK (the main pathway of cellular energy exchanges), are important in this metabolic-signaling network. These two signaling pathways control each other by $m$ TORC1 gene in the mTOR signaling path, so that increasing or decreasing the intracellular energy levels of AMPK signaling pathway with an inhibitory or activating effect on mTORC1 gene can cause anabolism or catabolism of lipids in cells (Fig. 7).

According to the ontology and functions of genes, which encode two signaling pathways, AMPK and PPAR, these two pathways are the main pathways of cellular energy exchange and lipid metabolism respectively.

Peroxisome proliferator-activated receptors (PPARs) are transcription factors belonging to the nuclear receptor superfamily, and they are activated by longchain unsaturated fatty acids with several double bonds, eicosanoids, and lipid-lowering agents such as fibrates. Among the unsaturated fatty acids with and double bonds, Eicosapentaenoic Acid (EPA) and Docosahexaenoic acid have been widely studied because of their ability to activate peroxisome proliferatoractivated receptors (PPARs). The expression profile of $P P A R_{\alpha}$ in different organs of poultry is largely similar to mammals, in such a way that it expresses similar functions of $P P A R_{\alpha}$ in poultry and mammals. Peroxisome proliferator-activated receptors (PPARs) are nuclear hormone receptors that are activate by fatty acids and their derivatives. Each of them is encoded in a separate gene and bind fatty acids and eicosanoids. Ligand property of PPAR-RXR heterodimers 
for fatty acids causes the binding of these heterodimers to "Specific Receptor Elements" in the promoter region of several genes and changes the transcription of downstream genes involved in immune processes, lipid metabolism, and cholesterol metabolism [65].

AMP-activated protein kinase (AMPK) is a serine/threonine kinase that has a high protective system. The AMPK system acts as a cellular energy sensor. When AMPK s activated, it simultaneously inhibits the energy consumption in biosynthetic pathways, such as protein, fatty acids, and glycogen synthesis and activates the catabolic pathways (breakdown) of ATP production, including the fatty acid oxidation and glycolysis [66]. The reduced regulation of liver AMPK activity plays a pathophysiological role in lipid metabolic disorders. However, the signaling pathway of AMPK for regulation of cellular energy balance is essential for the lipid metabolism, so that the pathway activates the catabolism of fat in the shortage of energy in the cell to provide the necessary rate of ATP. Therefore, the AMP-activated protein kinase (AMPK) is a main regulator of cell metabolism and metabolism organ in eukaryotes and it is activated by lowering the intra-cellular ATP level. AMPK plays an important role in the growth regulation and re-planning of cell metabolism [67].

\section{Conclusion}

The combination of Omics data for obtaining and identifying genes with differences in gene expression led to a successful identification of 1835 genes in abdominal fat tissue in two groups of broiler chickens with greater and lower abdominal fat storage. The same identified genes were involved in the signaling pathways of endocrine glands, AMPK, and PPAR associated with lipid metabolism and energy catabolism and could be considered as the genes that were similar in different species. The present study identified important common genes relating to the lipid metabolism and metabolic and signaling pathways, and detected the mechanisms associated with lipid transfer by different cell membranes and tissues by explanation of relevant genes. Furthermore, the gene-gene and gene-miRNA interactions were also examined by investigating the biological system and reconstruction of various regulatory and interactive networks. The overall result of study included the identification of 41 genes in the main process of metabolism (anabolism and catabolism), fat storage, and signaling pathway of endocrine glands, and the cell membrane. Furthermore, the gene interaction networks, interactive bipartite network of Gene-miRNA, and functional modules, and the metabolic-signaling network were reconstructed to identify metabolic and signaling pathways associated with the fat storage and metabolism.

\section{Declarations}

\section{ETHICS STATEMENT}

Ethical review and approval was not required for the animal study because this study is just analysis.

\section{AUTHOR CONTRIBUTIONS}

$\mathrm{FGH}, \mathrm{MS}, \mathrm{AB}$, and SRMA designed the study. FGH, MS, and $\mathrm{AB}$ carried out experimental procedures. FGH and $\mathrm{AB}$ analyzed the data and wrote the manuscript. MS, AB and SRMA supervised the study. All authors approved the final version of the manuscript.

\section{CONFLICT OF INTEREST}

The authors declare that the research was conducted in the absence of any commercial or financial relationships that could be construed as a potential conflict of interest.

\section{ACKNOWLEDGMENTS}

This work was financially supported by the University of Tehran, Iran. The authors thank all the teams who worked on the experiments and who provided technical assistance in the laboratory during this study. We also thank the anonymous reviewers whose critical comments helped in improving the manuscript.

\section{References}

1. Sakomura NK, Longo FA, Oviedo-Rondon EO, Boa-Viagem C, Ferraudo A. Modeling energy utilization and growth parameter description for broiler chickens. Poul Sci. 2005;84(9):1363-9.

2. Crespo N, Esteve-Garcia E. Dietary fatty acid profile modifies abdominal fat deposition in broiler chickens. Poul Sci. 2001;80(1):71-8.

3. Le Mignon G, Pitel F, Gilbert H, Le Bihan-Duval E, Vignoles F, Demeure O, et al. A comprehensive analysis of QTL for abdominal fat and breast muscle weights on chicken chromosome 5 using a multivariate approach. Anim Genet. 2009;40(2):157-64.

4. Lagarrigue S, Pitel F, Carré W, Abasht B, Le Roy P, Neau A, et al. Mapping quantitative trait loci affecting fatness and breast muscle weight in meat-type chicken lines divergently selected on abdominal fatness. Genet Selec Evol. 2006;38(1):85-97.

5. Pinto LF, Packer IU, Ledur MC, Moura AS, Nones K, Coutinho LL. Mapping quantitative trait loci in Gallus gallus using principal components. Revista Brasileira de Zootecnia. 2010;39(11):2434-41.

6. Nones K, Ledur MC, Zanella EL, Klein C, Pinto LF, Moura AS, et al. Quantitative trait loci associated with chemical composition of the chicken carcass. Anim Genet. 2012;43(5):570-6.

7. Cesar AS, Regitano LC, Reecy JM, Poleti MD, Oliveira PS, de Oliveira GB, et al. Identification of putative regulatory regions and transcription factors associated with intramuscular fat content traits. BMC Genomics. 2018;19(1):499-519.

8. Ji B, Ernest B, Gooding JR, Das S, Saxton AM, Simon J, et al. Transcriptomic and metabolomic profiling of chicken adipose tissue in response to insulin neutralization and fasting. BMC Genom. 2012;13(1):441. 
9. Ji B, Middleton JL, Ernest B, Saxton AM, Lamont SJ, Campagna SR, et al. Molecular and metabolic profiles suggest that increased lipid catabolism in adipose tissue contributes to leanness in domestic chickens. Physiol Genom. 2014;46(9):315-27.

10. Resnyk CW, Carré W, Wang X, Porter TE, Simon J, Le Bihan-Duval E, et al. Transcriptional analysis of abdominal fat in genetically fat and lean chickens reveals adipokines, lipogenic genes and a link between hemostasis and leanness. BMC Genom. 2013;14(1):557-83.

11. Bartel DP. MicroRNAs: genomics, biogenesis, mechanism, and function. Cell. 2004;116(2):281-97.

12. Iorio MV, Casalini P, Piovan C, Braccioli L, Tagliabue E. Breast cancer and microRNAs: therapeutic impact. The Breast. 2011;20:63-70.

13. Cole JB, Lewis RM, Maltecca C, Newman S, Olson KM, Tait RG. Systems Biology in Animal Breeding: Identifying Relationships among Markers, Genes, and Phenotypes. Breed Genet Sym. 2013;91:521-2.

14. Huang JC, Morris QD, Frey BJ. Detecting microRNA targets by linking sequence, microRNA and gene expression data. InAnnual International Conference on Research in Computational Molecular Biology. Springer, Berlin, Heidelberg. 2006;114-129.

15. Bahrami A, Miraie-Ashtiani SR, Sadeghi M, Najafi A. miRNA-mRNA network involved in folliculogenesis interactome: systems biology approach. Reproduction. 2017a;154(1):51-65.

16. Bahrami A, Miraie-Ashtiani SR, Sadeghi M, Najafi A, Ranjbar R. Dynamic modeling of folliculogenesis signaling pathways in the presence of miRNAs expression. J Ovar Res. 2017b;10(1):76-85.

17. Du P, Kibbe WA, Lin SM. lumi: a pipeline for processing Illumina microarray. Bioinformatics. 2008;24(13):1547-8.

18. Gautier L, Cope L, Bolstad BM, Irizarry RA. Affy-analysis of Affymetrix GeneChip data at the probe level. Bioinformatics. 2004;20(3):307-15.

19. Ritchie ME, Phipson B, Wu DI, Hu Y, Law CW, Shi W, et al. limma powers differential expression analyses for RNA-sequencing and microarray studies. Nucl Acids Res. 2015;43(7):e47.

20. Davis S, Meltzer PS. GEOquery: a bridge between the Gene Expression Omnibus (GEO) and BioConductor. Bioinformatics. 2007;23(14):1846-7.

21. Huber W, Carey VJ, Gentleman R, Anders S, Carlson M, Carvalho BS, et al. Orchestrating high-throughput genomic analysis with Bioconductor. Nat Meth. 2015;12(2):115.

22. FastQC: a quality control tool for high throughput sequence data Available Online at:

Andrews S. FastQC: a quality control tool for high throughput sequence data. 2010; Available Online at: http://www.bioinformatics.babraham.ac.uk/projects/fastqc.

23. Bolger AM, Lohse M, Usadel B. Trimmomatic: a flexible trimmer for Illumina sequence data. Bioinformatics. 2014;30(15):2114-20.

24. Kim D, Pertea G, Trapnell C, Pimentel H, Kelley R, Salzberg SL. TopHat2: accurate alignment of transcriptomes in the presence of insertions, deletions and gene fusions. Genome Biol. 2013;14(4):R36.

25. Trapnell C, Williams BA, Pertea G, Mortazavi A, Kwan G, Van Baren MJ, et al. Transcript assembly and quantification by RNA-Seq reveals unannotated transcripts and isoform switching during cell differentiation. Nat Biotech. 2010;28(5):511-5.

26. Sherman BT, Lempicki RA. Systematic and integrative analysis of large gene lists using DAVID bioinformatics resources. Nat Prot. 2009;4(1):44-57.

27. Raudvere U, Kolberg L, Kuzmin I, Arak T, Adler P, Peterson H, et al. g: Profiler: a web server for functional enrichment analysis and conversions of gene lists (2019 update). Nuc. Acids Rese. 2019;47(W1):W191-8.

28. Mi H, Muruganujan A, Thomas PD. PANTHER in 2013: modeling the evolution of gene function, and other gene attributes, in the context of phylogenetic trees. Nucleic Acids Res. 2012;41(D1):D377-86.

29. Shen L, Han J, Wang H, Meng Q, Chen L, Liu Y, et al. Cachexia-related long noncoding RNA, CAAlnc1, suppresses adipogenesis by blocking the binding of HuR to adipogenic transcription factor mRNAs. Int J Cancer. 2019;145(7):1809-21.

30. Kozomara A, Birgaoanu M, Griffiths-Jones S. miRBase: from microRNA sequences to function. Nucleic Acids Res. 2019;47(D1):D155-62.

31. Sticht C, De La Torre C, Parveen A, Gretz N. miRWalk: An online resource for prediction of microRNA binding sites. PloS One. 2018;13(10).

32. Agarwal V, Bell GW, Nam JW, Bartel DP. Predicting effective microRNA target sites in mammalian mRNAs. Elife. 2015;4:e05005.

33. Szklarczyk D, Gable AL, Lyon D, Junge A, Wyder S, Huerta-Cepas J, et al. STRING v11: protein-protein association networks with increased coverage, supporting functional discovery in genome-wide experimental datasets. Nucl Acids Res. 2019;47(D1):D607-13.

34. Warde-Farley D, Donaldson SL, Comes O, Zuberi K, Badrawi R, Chao P, et al. The GeneMANIA prediction server: biological network integration for gene prioritization and predicting gene function. Nucl Acids Res. 2010;38(suppl_2):W214-20.

35. Shannon P, Markiel A, Ozier O, Baliga NS, Wang JT, Ramage D, et al. Cytoscape: a software environment for integrated models of biomolecular interaction networks. Genome Res. 2003;13(11):2498-504.

36. Funahashi A, Matsuoka Y, Jouraku A, Morohashi M, Kikuchi N, Kitano H. CellDesigner 3.5: a versatile modeling tool for biochemical networks. Proceedings of the IEEE. 2008;96(8):1254-65.

37. Lotia S, Montojo J, Dong Y, Bader GD, Pico AR. Cytoscape app store. Bioinformatics. 2013;29(10):1350-1.

38. Resnyk CW, Chen C, Huang H, Wu CH, Simon J, Le Bihan-Duval E, et al. RNA-Seq analysis of abdominal fat in genetically fat and lean chickens highlights a divergence in expression of genes controlling adiposity, hemostasis, and lipid metabolism. PloS One. 2015;10(10).

39. Almkvist O, Rodriguez-Vieitez E, Thordardottir S, Nordberg A, Viitanen M, Lannfelt L, et al. Longitudinal cognitive decline in autosomal-dominant Alzheimer's disease varies with mutations in APP and PSEN1 genes. Neurobiol Aging. 2019;82:40-7.

40. Wang YZ, Yang L, Li CF. Protective effect of atorvastatin meditated by HMGCR gene on diabetic rats with atherosclerosis: An in vivo and in vitro study. Biomed Pharma. 2018;104:240-51.

Page $12 / 19$ 
41. Chen X, Wu Y, Zhang Z, Zheng X, Wang Y, Yu M, et al. Effects of the rs3834458 Single Nucleotide Polymorphism in FADS2 on Levels of $n$-3 Long-chain Polyunsaturated Fatty Acids: A Meta-analysis. Prostaglandins, Leukotrienes and Essential Fatty Acids. 2019; 1-6.

42. Calvo JH, González-Calvo L, Dervishi E, Blanco M, Iguácel LP, Sarto P, et al. A functional variant in the stearoyl-CoA desaturase (SCD) gene promoter affects gene expression in ovine muscle. Livestock Sci. 2019;219:62-70.

43. Chanyshev MD, Razumova YV, Ovchinnikov VY, Gulyaeva LF. MiR-21 regulates the ACAT1 gene in MCF-7 cells. Life Sci. 2018;209:173-8.

44. Diebold I, Schön U, Horvath R, Schwartz O, Holinski-Feder E, Kölbel H, et al. HADHA and HADHB gene associated phenotypes-Identification of rare variants in a patient cohort by Next Generation Sequencing. Mol Cell Prob. 2019;44:14-20.

45. Assmann N, Dettmer K, Simbuerger JM, Broeker C, Nuernberger N, Renner K, et al. Renal Fanconi syndrome is caused by a mistargeting-based mitochondriopathy. Cell Rep. 2016;15(7):1423-9.

46. Jung UJ, Choi MS. Obesity and its metabolic complications: the role of adipokines and the relationship between obesity, inflammation, insulin resistance, dyslipidemia and nonalcoholic fatty liver disease. Int J Mol Sci. 2014;15(4):6184-223.

47. Aali M, Moradi-Shahrbabak H, Moradi-Shahrbabak M, Sadeghi M, Kohram H. Polymorphism in the SCD gene is associated with meat quality and fatty acid composition in Iranian fat-and thin-tailed sheep breeds. Livestock Sci. 2016;188:81-90.

48. Song Q, Song J, Li C, Liu Z, Wang Y, Qi L, et al. Physical activity attenuates the association between the IRS1 genotype and childhood obesity in Chinese children. Nutr Metab Cardiovascular Dis. 2019;29(8):793-801.

49. Stachowiak M, Nowacka-Woszuk J, Szydlowski M, Switonski M. The ACACA and SREBF1 genes are promising markers for pig carcass and performance traits, but not for fatty acid content in the longissimus dorsi muscle and adipose tissue. Meat Sci. 2013;95(1):64-71.

50. Gillies PJ. Preemptive nutrition of pro-inflammatory states: A nutrigenomic model. Nutr Rev. 2007;65(suppl_3):217-20.

51. Brown JD, Plutzky J. Peroxisome proliferator-activated receptors as transcriptional nodal points and therapeutic targets. Circulation. 2007;115(4):51833.

52. Boucher J, Kleinridders A, Kahn CR. Insulin receptor signaling in normal and insulin-resistant states. Cold Spring Harb Perspect Biol. 2014;6(1):a009191.

53. Di Camillo B, Carlon A, Eduati F, Toffolo GM. A rule-based model of insulin signalling pathway. BMC Syst Biol. 2016;10(1):38-51.

54. Shi X, Wang J, Lei Y, Cong C, Tan D, Zhou X. Research progress on the PI3K/AKT signaling pathway in gynecological cancer. Mol. Med. Rep. 2019;19(6):4529-35.

55. Laplante M, Sabatini DM. mTOR signaling at a glance. J Cell Sci. 2009;122(20):3589-94.

56. Puig KL, Brose SA, Zhou X, Sens MA, Combs GF, Jensen MD, et al. Amyloid precursor protein modulates macrophage phenotype and diet-dependent weight gain. Sci Rep. 2017;7:43725.

57. Ghafouri F, Sedeghi M, Bahrami A. Long Non-Coding RNAs (LncRNAs): Roles, Functions, and Mechanisms. Genetic Engineering Biosafety Journal. 2018;7(2):245-66.

58. Faghihi MA, Modarresi F, Khalil AM, Wood DE, Sahagan BG, Morgan TE, et al. Expression of a noncoding RNA is elevated in Alzheimer's disease and drives rapid feed-forward regulation of $\beta$-secretase. Nat Med. 2008;14(7):723-30.

59. Ramakrishnan V, Husain RA, Ahmed SS. PSEN1 gene polymorphisms in Caucasian Alzheimer's disease: A meta-analysis. Clin Chim Acta. 2017;473:6570.

60. Muchnik C, Olivar N, Dalmasso MC, Azurmendi PJ, Liberczuk C, Morelli L, et al. Identification of PSEN2 mutation p. N141I in Argentine pedigrees with early-onset familial Alzheimer's disease. Neurobiol Aging. 2015;36(10):2674-7.

61. Yu Y, Jia J. Lack of association between the polymorphisms of $\beta$-site APP-cleaving enzyme 2 (BACE2) 5'-flanking region and sporadic Alzheimer's disease. Brain Res. 2009;1257:10-5.

62. Snowden SG, Ebshiana AA, Hye A, An Y, Pletnikova O, O’Brien R, et al. Association between fatty acid metabolism in the brain and Alzheimer disease neuropathology and cognitive performance: A nontargeted metabolomic study. PLoS Med. 2017;14(3).

63. Morris MC, Evans DA, Bienias JL, Tangney CC, Bennett DA, Aggarwal N, et al. Dietary fats and the risk of incident Alzheimer disease. Arch Neurol. 2003;60(2):194-200.

64. Begic N, Begic Z, Begic E. DHCR7 gene mutation-Bosnian and Herzegovinian experience. Atherosclerosis. 2019;287:e223.

65. Zoete V, Grosdidier A, Michielin O. Peroxisome proliferator-activated receptor structures: ligand specificity, molecular switch and interactions with regulators. Biochim Bioph Acta (BBA)-Mol Cell Biol Lipids. 2007;1771(8):915-25.

66. Miyamoto L, Ebihara K, Kusakabe T, Aotani D, Yamamoto-Kataoka S, Sakai T, et al. Leptin Activates Hepatic 5'-AMP-activated Protein Kinase through Sympathetic Nervous System and a1-Adrenergic Receptor a potential mechanism for improvement of fatty liver in lipodystrophy by leptin. J Biol Chem. 2012;287(48):40441-7.

67. Mihaylova MM, Shaw RJ. The AMPK signalling pathway coordinates cell growth, autophagy and metabolism. Na Cell Biol. 2011;13(9):1016-23.

68. Resnyk CW, Carré W, Wang X, Porter TE, Simon J, Le Bihan-Duval E, et al. Transcriptional analysis of abdominal fat in chickens divergently selected on bodyweight at two ages reveals novel mechanisms controlling adiposity: validating visceral adipose tissue as a dynamic endocrine and metabolic organ. BMC Genomics. 2017;18(1):626.

69. Cogburn LA, Porter TE, Duclos MJ, Simon J, Burgess SC, Zhu JJ, et al. Functional genomics of the chicken-a model organism. Poul Sci. 2007;86(10):2059-94.

70. Byerly MS, Simon J, Cogburn LA, Le Bihan-Duval E, Duclos MJ, Aggrey SE, et al. Transcriptional profiling of hypothalamus during development of adiposity in genetically selected fat and lean chickens. Physiol Genom. 2010;42(2):157-67. 
71. Bourneuf E, Hérault F, Chicault C, Carré W, Assaf S, Monnier A, et al. Microarray analysis of differential gene expression in the liver of lean and fat chickens. Gene. 2006;372:162-70.

\section{Figures}

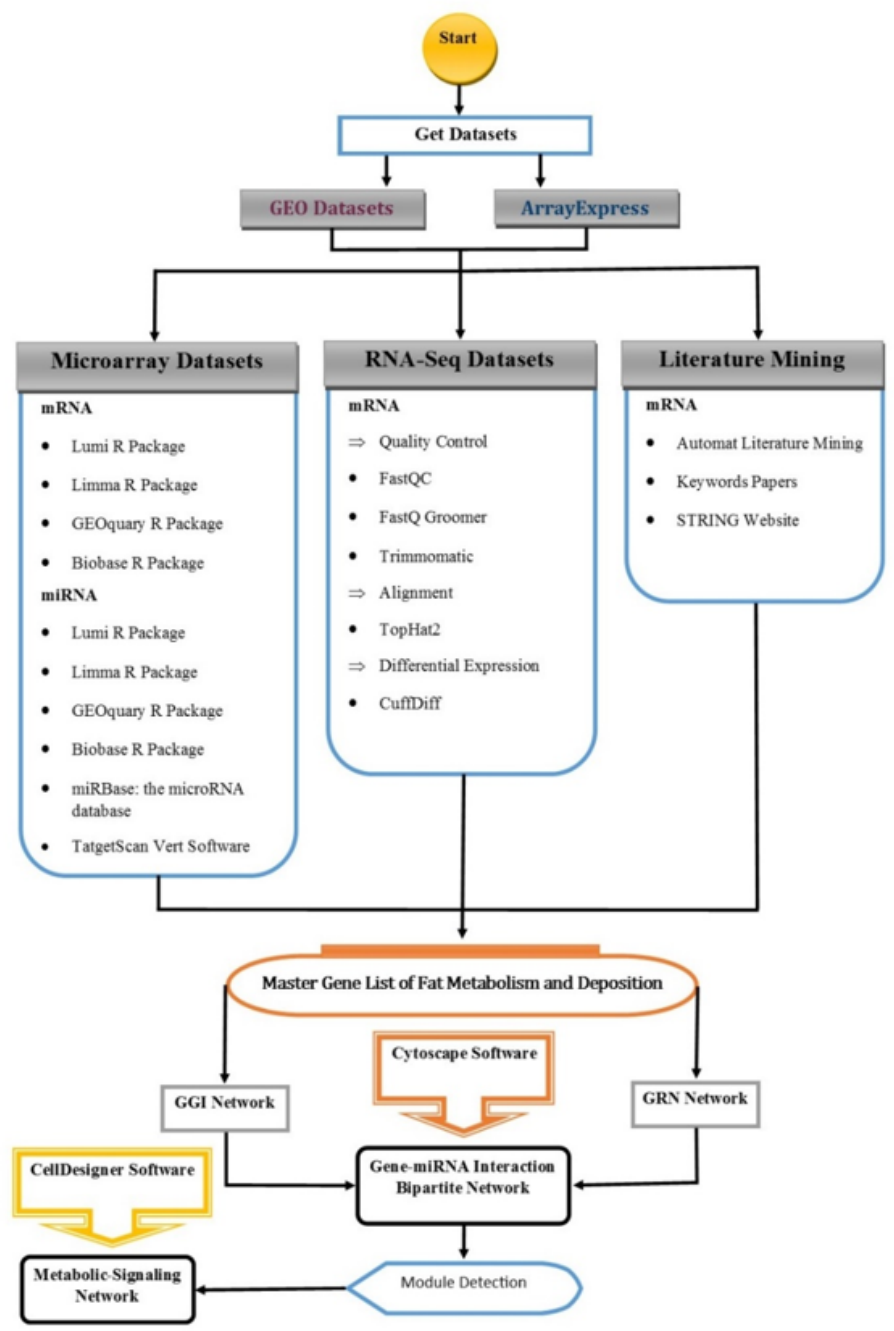

Figure 1

Schematic view of the workflow to reconstruct the metabolic pathways of abdominal fat storage in poultry. The main gene list was prepared from three RNASeq and microarray data sets. The Gene-gene Interaction Network (GGI), Gene Regulatory Network (GRN) and interactive bi-partite network of Gene-miRNA network were reconstructed using Cytoscape. Functional modules were detected using related plugin in Cytoscape and the metabolic-signaling network using CellDesigner. 


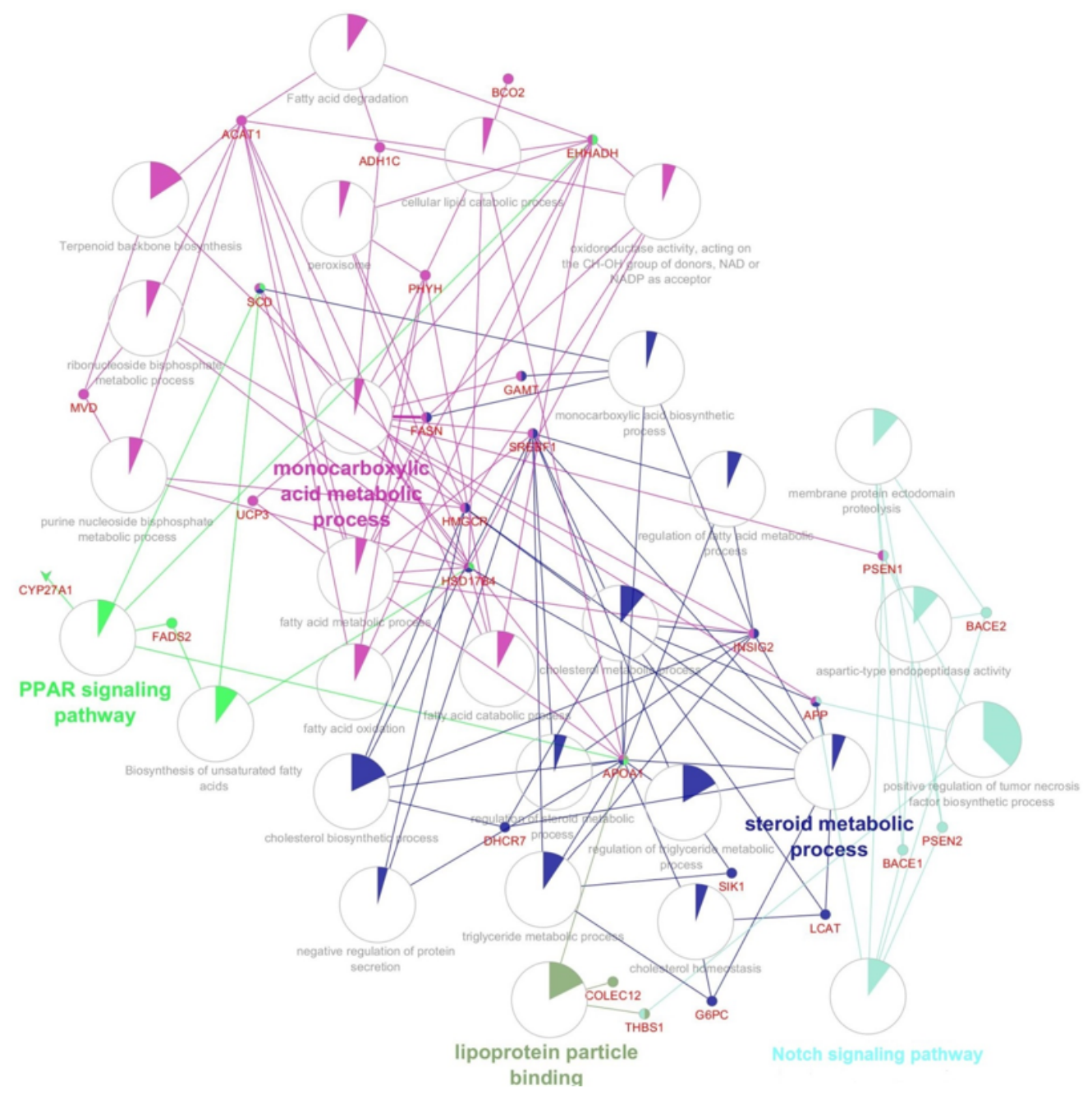

Figure 2

The Gene, Gene Ontology and pathway, related interaction network involved in the abdominal fat storage of the poultry. 


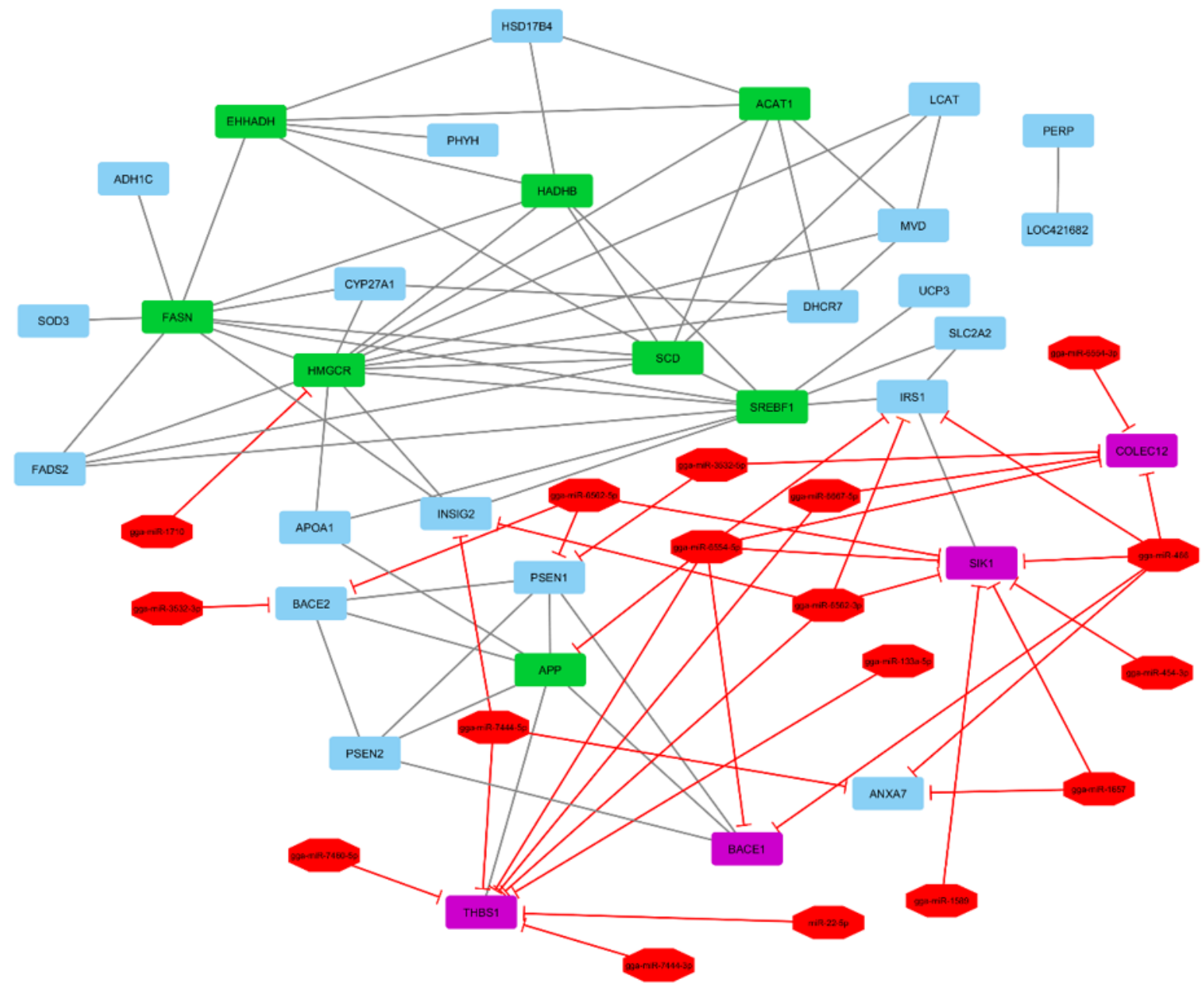

\section{Figure 3}

Interactive bipartite network (Gene-miRNA) affecting the abdominal fat storage and metabolism in the poultry. In this network, the quadrilateral points represent genes and the octagonal points represent miRNAs. About miRNAs and target genes, the edges indicate the suppressing role of miRNAs. The edges also represent the gene-gene interactions. The green quadrilateral nodes represent the hub genes. Purple quadrilateral nodes are the genes with the heist suppression by miRNAs. 


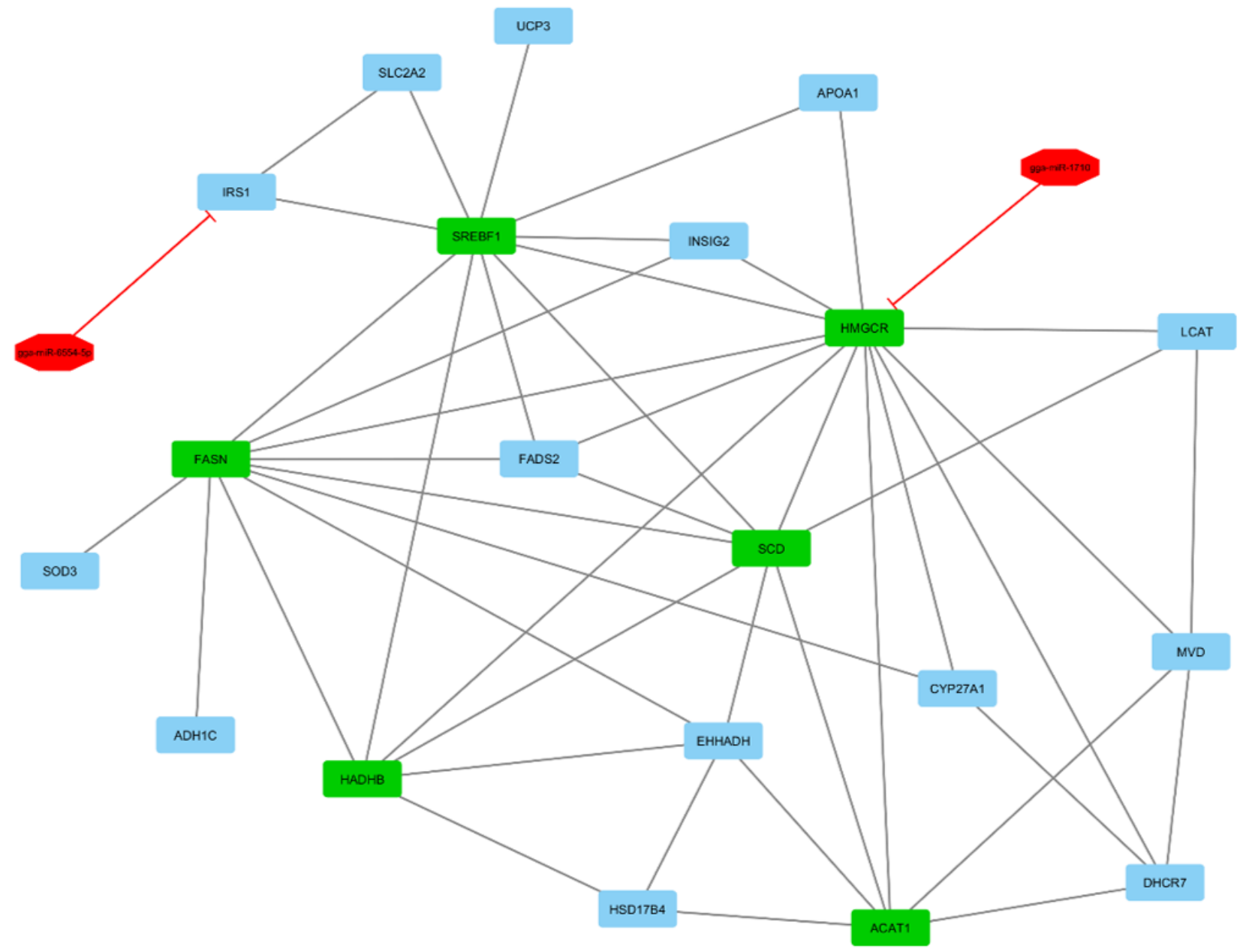

\section{Figure 4}

Module 1: 20 genes and 2 miRNAs in the interactive bipartite network of Gene-miRNA. In this network, the quadrilateral points represent the genes and the octagonal points represent miRNAs. In this interactive bipartite network, the Gene-miRNAs of quadrilateral nodes represent genes and octagonal nodes represent miRNAs. For miRNAs and target genes, the edges indicate the suppressing roles of miRNAs. The edges of genes also indicate the gene-gene interactions. The green quadrilateral nodes represent the hub genes. Purple quadrilateral nodes have the highest rates of suppression by miRNAs. 


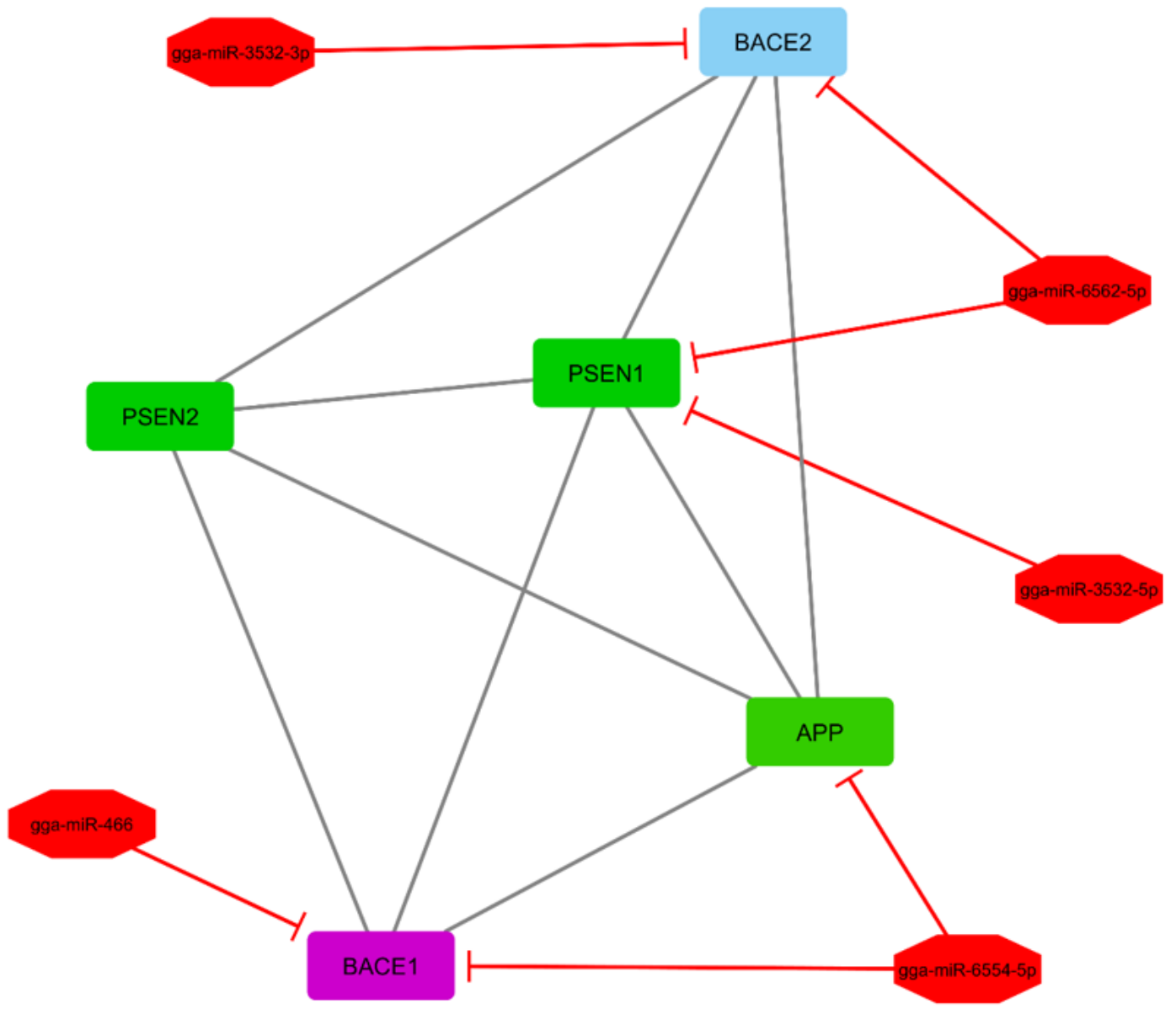

Figure 5

Module 2: 5 genes and 5 miRNAs in the interactive bipartite network of Gene-miRNA. In this network, the quadrilateral points represent genes; and the octagonal points represent miRNAs. In this interactive bipartite network of Gene-miRNA, quadrilateral nodes represent genes; and octagonal nodes represent the miRNAs. For miRNAs and target genes, the edges indicate the suppressing roles of miRNAs. The edges of genes also indicate the gene-gene interactions. The green quadrilateral nodes represent the genes with the highest gene-gene interactions with other genes in the network (or hub genes). Purple quadrilateral nodes indicate the genes with the highest suppression by miRNAs. 


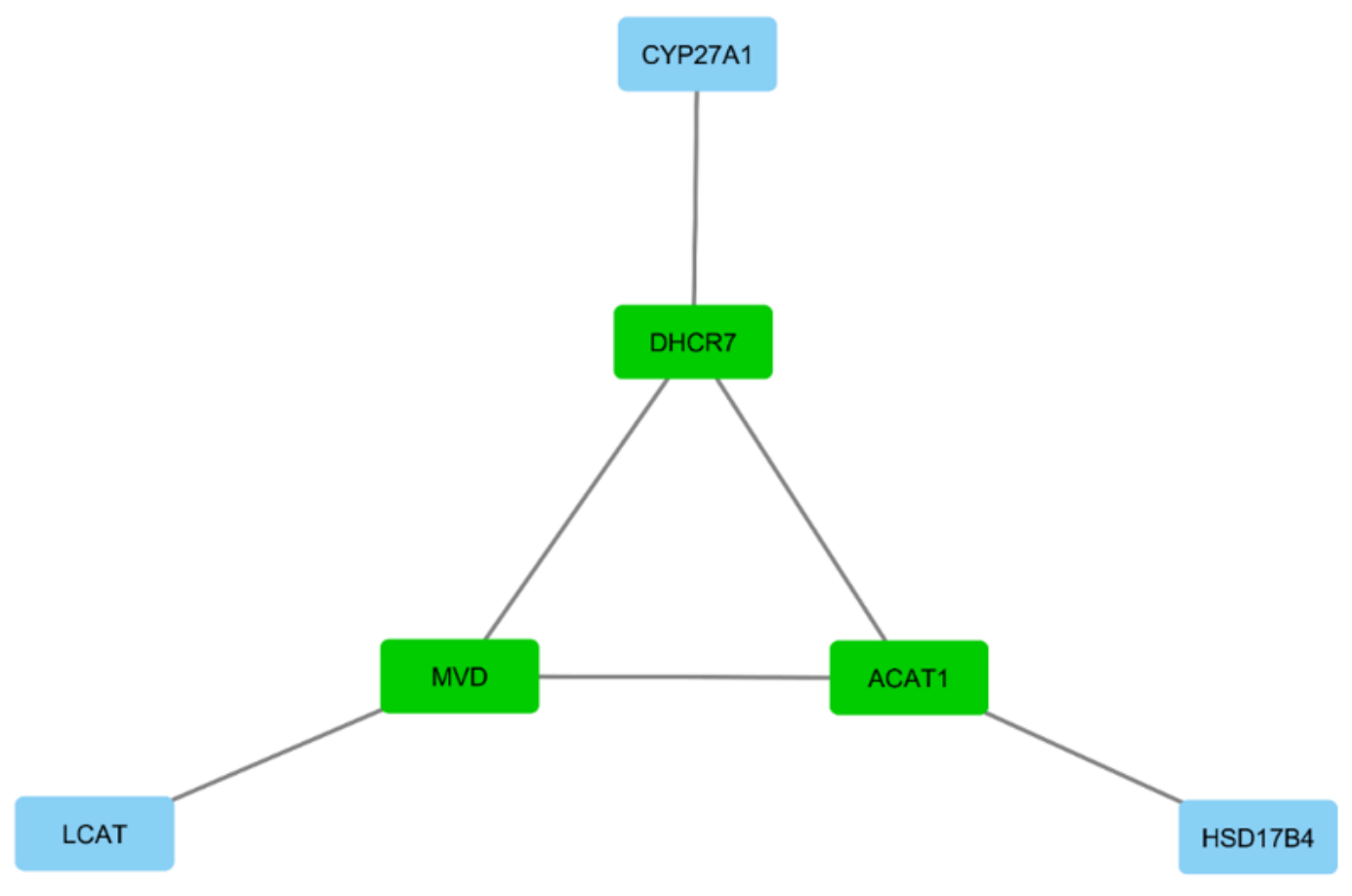

\section{Figure 6}

Module 3: 6 genes in interactive bipartite network of Gene-miRNA. In this network, the quadrilateral nodes represent genes; and edges indicate the gene-gene interaction effects. Green quadrilateral nodes represent the hub genes in the network. Blue nodes represent other genes in the network.

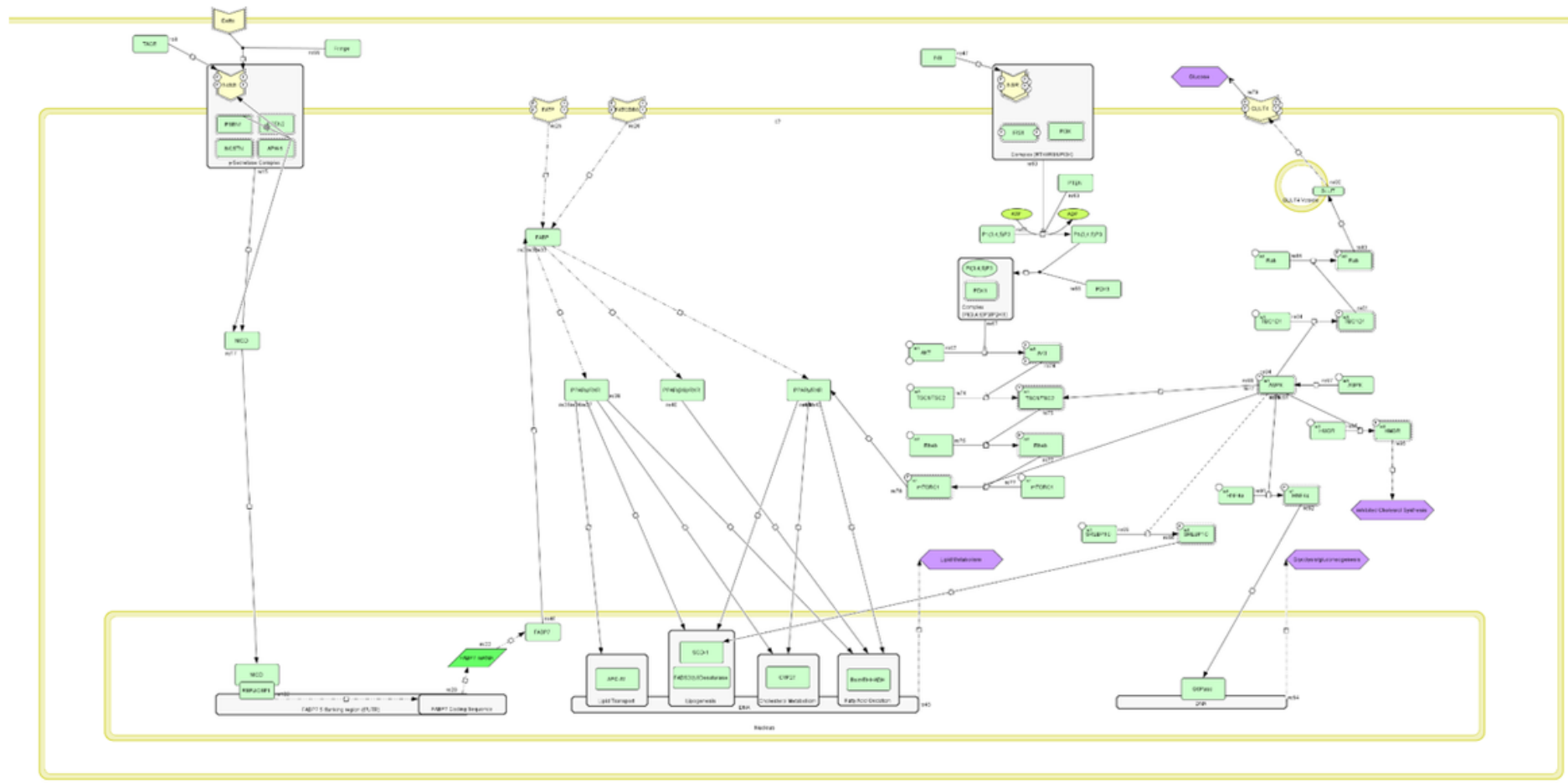

Figure 7

Schematic of the regenerated metabolic-signaling network associated with fat metabolism and storage using CellDesigner.

Page $19 / 19$ 